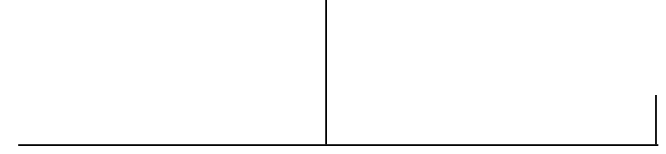

Rev. Latinoam. Psicopat. Fund., São Paulo, v. 14, n. 3, p. 419-425, setembro 2011

\title{
Editorial
}

\section{Morte sem futuro e morte com futuro. A questão do tempo na morte}

Manoel Tosta Berlinck

Lendo a tese de Doutorado de Sandra Luzia de Souza Alencar, A experiência do luto em situação de violência: entre duas mortes, defendida no Programa de Pós-Graduação em Psicologia Social da Pontifícia Universidade Católica de São Paulo, no dia 20 de maio de 2011, lembrei-me de breve conversa que tive com uma balconista numa padaria.

Ela havia acabado de dar um saquinho de pães para um morador de rua e comentou o ato comigo: "Coitado, ele não tem futuro".

Escutei esse comentário como uma obscura consigna, ou seja, "coitados daqueles que não têm futuro".

A tese de Sandra Alencar tem como ponto de partida a experiência profissional de sua autora em instituições sociais de assistência a crianças e adolescentes em situação de ameaça e perigo de vida, e toma um fragmento de caso clínico que atendeu num CAPS, em outro momento de sua carreira profissional.

Flor é uma mulher negra, com 47 anos de idade, trabalhadora na área da saúde, moradora num bairro da periferia da cidade de São Paulo. Chega a um serviço público de saúde mental por intermédio de uma colega de trabalho, que anuncia o sofrimento de Flor: depressão. 
Na primeira entrevista, Flor relata seus sintomas: está insone, não conversa, não tem vontade de nada, não consegue respirar, diz-se sufocada. Em uma consulta psiquiátrica recebe o diagnóstico de depressão. Passa a tomar antidepressivos, mas não melhora.

Do que sofre essa mulher? Qual o seu pathos? O sintoma foi denominado, mas e o sofrimento?

O filho de Flor foi assassinado há pouco tempo. As circunstâncias em que encontrou o filho morto são as seguintes: "Ele não dormiu em casa, quando passei em casa para me trocar para ir para o meu outro emprego [Flor trabalha em dois empregos, em um deles faz plantões noturnos] fiquei sabendo. Aí quando cheguei lá [na instituição onde trabalha] fiquei ligando para o telefone celular dele, mas ele não atendia... Eu fiquei ligando... aí uma mulher atendeu e ela me perguntou se eu conhecia o dono daquele telefone, porque ele estava morto, caído lá no chão" (p. 21).

Após ter a notícia da morte do filho, Flor foi com o marido ao local indicado. O filho estava ali, diz Flor: "Estava ali, jogado no chão, morto, morto como um cachorro".

A autora da tese prossegue: "Flor é católica, mas não encomendou missa, também não cuidou da sepultura, não foi ao enterro. Diz não conversar com os vizinhos nem com as colegas de trabalho. Não atende ao telefone, recusa que se relaciona com o medo" (p. 22).

E termina o relato sobre o episódio da morte do filho: "Ao ir à delegacia de polícia, já que queria saber quem matou seu filho, recebe a seguinte resposta da autoridade policial: "Nestes casos é melhor não mexer, é melhor deixar isso para lá” (p. 22).

Enquanto lia a tese, minha atenção foi atraída por anúncio fúnebre publicado no jornal $O$ Estado de S. Paulo, no dia 14 de maio de 2011:

O Príncipe D. Luiz de Orleans e Bragança, Chefe da Casa Imperial do Brasil, profundamente consternado, comunica, em seu próprio nome, assim como em nome de seus irmãos, respectivos cônjuges, filhos e netos, bem como em nome de todos os demais familiares, o falecimento de sua muito querida mãe, sogra, avó e bisavó Sua Alteza Imperial e Real, Dona Maria Elizabeth da Baviera de Orleans e Bragança, Princesa da Baviera, Dama de Honra da Real Ordem Bávara Elisabetana e da Real Ordem Bávara Teresiana, que, hoje, 13 de maio de 2011, no Rio de Janeiro, depois de uma vida longa e plenamente realizada, aos 96 anos de idade, confortada com os sacramentos da Santa Igreja e a bênção de Sua Santidade, Deus Nosso Senhor teve por bem chamar a Si.

A falecida era filha do Príncipe Francisco da Baviera e da Princesa Elizabeth de Crö̈, tendo nascido a 9 de setembro de 1914. Casou-se em 19 de agosto de 
1937 com o Príncipe Pedro Henrique de Orleans e Bragança, falecido em 1981, primogênito do Príncipe Luiz de Orleans e Bragança e neto da Princesa Isabel, a Redentora, a quem sucedeu na Chefia da Casa Imperial do Brasil.

As exéquias serão realizadas na cidade de Vassouras, RJ, no dia 14 de maio. Velório, a partir das 10 horas, na Igreja Matriz de Nossa Senhora da Conceição; Missa de corpo presente, na mesma Matriz, às 12 horas; e sepultamento no jazigo da Família, no Cemitério da Irmandade de Nossa Senhora da Conceição, às 14 horas.

As missas de $7^{\circ}$ dia serão celebradas no Rio de Janeiro na Igreja Nossa Senhora do Carmo da Antiga Sé - Rua $1^{\circ}$ de Março, Centro, às 12 horas da quintafeira, dia 19 de maio; e, em São Paulo, na Igreja Nossa Senhora do Brasil, no Jardim América, às 12:45 horas da sexta-feira, dia 20 de maio.

Caixa Postal 1590 CEP 01031-970 São Paulo, SP. E-mail: condolências@casaimperialdobrasil.org

Morte seca, morte úmida. Morte sem futuro e morte com futuro?

A morte é tão mais seca e silenciosa quanto mais anônima é.

A infinita distância social entre esses dois obituários fala da existência de dois Brasis: de um lado o Brasil dos que não têm futuro e, de outro, o Brasil dos que têm futuro.

A esta altura alguém pode estar se perguntando: "Mas, afinal, que história é essa? Existe futuro na morte?"

Em "Considerações atuais sobre a guerra e a morte", Freud (1915) faz o seguinte comentário: "Cada um de nós deve à natureza uma morte e tem de estar preparado para saldar a dívida, em suma, a morte é natural, incontestável e inevitável. Mas, na realidade, agimos como se as coisas fossem diferentes. Pomos a morte de lado. Eliminamos a morte da vida" (p. 230). Freud acredita que há, no humano, uma exigência de imortalidade. Como, então, seria possível se preparar para a morte? A resposta dele é, no mínimo, desapontante, mas é o possível: devemos pensar cotidianamente na própria morte.

Sandra Alencar certamente concordaria com essa passagem, mas levanta, sem explicitar, uma questão fundamental: "O que seria a morte natural?" Pois defende a tese de que a morte não é processo natural, mas social (p. 2). Ora, se a morte é social, ela não é natural. Ou será que ela é natural e social?

Sandra vai além: “... a depender das circunstâncias, a realidade dá prova de que não há perda com a morte. Nestes casos, ao invés da afirmação da perda, que atua no indivíduo com força de desligamento do objeto de amor perdido, o que há é a negação de perda sofrida" (p. 3).

Questão, desde logo, complexa e contraditória e que, por isso mesmo, merece comentário. 
O primeiro comentário que gostaria de fazer é que Freud é bem mais radical que Sandra.

Para ela, a morte pode ser negada. A negação é um mecanismo intrapsíquico de defesa contra a dor provocada pela morte. Trata-se de recusa da realidade. Já para Freud, a morte é inacessível ao humano porque este apresenta uma exigência de imortalidade. O luto é, neste caso, um sentimento normal e passageiro e na melancolia não há luto.

Porém, a morte existe tanto para Freud quanto para Sandra.

Parece, então, que a questão colocada na tese de Sandra refere-se à maneira como lidamos com a morte, ou seja, como lidamos com a nossa exigência de imortalidade.

Como já foi dito, Freud recomenda que devemos nos preparar para nossa própria morte refletindo sobre ela a cada dia. Sandra, por outro lado, lembra que a morte é sempre súbita, inesperada e violenta, e, assim, não há como nos preparar.

O tema da morte ocupa, pois, os vivos e não os mortos. Esta frase, aparentemente banal supõe, entretanto, uma obscura complexidade. São os vivos que devem se preparar para a morte. Mas, depois de sua morte, restam os vivos que sobrevivem. Lidar com a morte pode significar, portanto, se preparar e pode significar se consolar.

Essas duas questões - o preparo para a morte e a lida dos sobreviventes são tratadas por muitos.

A consolação é tratada, por exemplo, por Sêneca, o grande filósofo estoico em "Consolação a Márcia". A pessoa consolada em questão era a filha de um senador que, uma dúzia de anos antes, havia visto seu livro sobre as guerras civis condenado e se suicidara. Márcia perdeu um de seus quatro filhos e, três anos depois, Sêneca escreveu para convencê-la de que não deveria prolongar o sofrimento desencadeado com a morte. Segundo o eminente professor desta casa e Editor Associado da Revista Latinoamericana de Psicopatologia Fundamental, onde "Consolação a Márcia" foi publicado, Paulo José Carvalho da Silva (2007), "Hoje, talvez, chamássemos tal procedimento de aconselhamento psicológico ou terapia breve por meio do fortalecimento do Eu. Naquele tempo, o emprego do discurso em um diálogo, a fim de ensinar a superação racional das paixões tristes e dores da alma chamava-se consolação" (p. 147).

A consolação está ausente no caso Flor, e seria importante uma reflexão sobre a impossibilidade desse cuidado na morte sem futuro. Deixo, entretanto, esta questão de lado porque quero examinar uma outra.

Para isso, lembro as palavras do padre Antonio Vieira no "Sermão da quarta dominga depois da Páscoa" pregado no Maranhão, em data desconhecida, publicado também na Revista Latinoamericana de Psicopatologia Fundamental. 
O Sermão de Vieira trata da infinita tristeza do humano diante da morte. O tema do Sermão é, pois, num primeiro momento, a tristeza. Paulo José Carvalho da Silva, ao introduzir o Sermão de Vieira na referida revista, chega a afirmar: "Poucas expressões da história da cultura brasileira foram tão eloquentes ao abordar o tema da tristeza como o "Sermão da quarta dominga depois da Paschoa". (p. 533)

Vieira promete, nesse sermão, ensinar a arte de não estar triste. Para tanto, realiza uma caracterização minuciosa da tristeza.

Há mais de trezentos anos, ele se valeu de convincentes imagens para fazer seu leitor reconhecer os sinais mais importantes da tristeza, quase como se pintasse uma tela com pinceladas precisas o suficiente para ainda impressionar pela acuidade e verossimilhança. Lê-se, nesse sermão, que a intimidade com a melancolia e o tédio, a anestesia dos sentidos, o esmaecimento do corpo, o aborrecimento com o mundo e com si mesmo, a perda do desejo e, sobretudo, o desgosto pela vida e a hipersensibilidade à dor compõem o quadro sombrio do padecimento da tristeza.

Na visão de Vieira, a tristeza e outros afetos são considerados naturais e universais, pois são próprios da condição humana. O humano é triste por dois motivos: nasce desamparado e está confrontado com a morte. Como, então, se livrar dessa infinita tristeza, pergunta Vieira.

Esta é uma questão psicopatológica da maior importância, pois ninguém antes e ninguém depois de Vieira se propôs a terminar com a tristeza. O poeta Vinicius de Moraes, por exemplo, declara a infinitude desse afeto numa canção cantada por todos nós.

Vieira, como grande pregador, procede retoricamente, ou seja, alcança seus interlocutores com argumentos convincentes. Oferece, para isso, uma explicação para a causa da tristeza, extraindo-a do campo teológico. Ele retoma o momento no qual Cristo teria anunciado sua morte aos apóstolos, que se entristeceram por se sentirem imediatamente saudosos e desamparados.

Porém, prossegue Vieira, o verdadeiro motivo de sentirem-se tristes não seria a ausência iminente do mestre amado, e sim o silêncio perante sua partida. Se eles tivessem se perguntado para onde iria Cristo teriam compreendido que não tinham motivos reais para tristeza.

O remédio para a tristeza, afeto que assola o humano diante da morte, é a vida eterna, a eternidade. A tristeza, assolando tanto os que irão morrer quanto os que irão sobreviver, só se desfaz se o humano almejar a eternidade.

A busca da vida eterna pela religião é, de fato, aquilo que retira o humano de sua infinita tristeza. A esse respeito seria interessante reler A ética protestante e o espírito do capitalismo de Max Weber. Introduzindo a predestinação - con- 
ceito próprio do calvinismo - e os sinais que ela oferece durante a vida, Weber não estaria oferecendo, também, um remédio para a infinita tristeza, além de especular sobre o espírito do capitalismo?

Mas, como resolver esta questão quando nos deparamos com pessoas que não acreditam nem em Deus nem numa vida depois da morte?

Para os agnósticos restam, provavelmente, três saídas interligadas.

A primeira é proposta por Freud quando afirma que Deus é uma criação projetiva do humano. Atribui-se a Deus propriedades que são do humano, mas que este não suporta reconhecer como tais, por serem muito assustadoras.

A segunda saída é o trabalho criativo, ou seja, aquilo que poderia ser chamado de sublimação. Sem religião e sem Deus, o sinal da salvação é a eternidade da obra. Os produtores, os que trabalham criando uma obra cuja existência ultrapassa a vida do criador, se eternizam na obra. O fruto de seu trabalho ultrapassa sua existência garantindo uma vida, se não eterna, mais longa do que sua morte. Nesse caso, não há motivo para tristeza, pois há obra.

A terceira saída é a prole, são os herdeiros, aqueles que prolongam a existência dos antepassados na memória onto e filogenética.

Quando um filho morre durante a vida dos antepassados, o luto deixa de ser um afeto passageiro porque o futuro se interrompe. Se o filho é único, então, como no caso Flor, o sentimento que se abate sobre os pais é a ausência de futuro.

Talvez isso explique a figura da tristeza de Flor. A morte do filho acaba com o futuro - tanto do filho quanto do pais - e não há o que comemorar. Sobra o silêncio.

Para os que não têm futuro resta a melancolia, este afeto sem futuro, onde o tempo inexiste. Sem religião e sem possibilidade de construir uma obra, só lhes resta a infinita tristeza de uma existência insignificante e sem sentido. Afinal, aos que tudo têm tudo lhes será dado e aos que nada têm tudo lhes será tirado.

Sandra, ao escrever esta magnífica tese de Doutorado, que deveria ser publicada, se livra da infinita tristeza com a sua capacidade criadora.

\section{Referências}

Freud, S. (1915). Considerações atuais sobre a guerra e a morte. In: Obras completas, Trad. de Paulo César de Souza. São Paulo: Companhia das Letras, 2010. V. 12. SÊNeCA. Consolação a Márcia. Revista Latinoamericana de Psicopatologia Fundamental, São Paulo, v. X, n. 1, p. 156-181, mar. 2007. 
VIEIRA, Padre Antonio. Sermão da quarta dominga depois da Paschoa. Revista Latinoamericana de Psicopatologia Fundamental, São Paulo, v. IX, n. 3, p. 538-564, set.2006.

\section{Manoel Tosta Berlinck (Jun/2011)}

Sociólogo, psicanalista, Ph.D. (Cornell University, Ithaca, N.Y., USA), professor da Universidade Estadual de Campinas (Unicamp, Campinas, SP/Br.) (1972 - 1992), Professor do Departamento de Psicologia do Desenvolvimento da Faculdade de Ciências Humanas e da Saúde da Pontifícia Universidade Católica de São Paulo (PUC-SP/Br); Professor do Programa de Estudos Pós-Graduados em Psicologia Clínica da Faculdade de Ciências Humanas e da Saúde da Pontifícia Universidade Católica de São Paulo (PUC-SP/Br.), onde dirige, desde 1995, o Laboratório de Psicopatologia Fundamental, presidente da Associação Universitária de Pesquisa em Psicopatologia Fundamental - AUPPF (2002-2012), editor responsável de Pulsional Revista de Psicanálise (1987-2009) e da Revista Latinoamericana de Psicopatologia Fundamental, membro da World Association of Medical Editors - WAME (Associação Mundial de Editores Médicos), diretor da Livraria Pulsional - Centro de Psicanálise (1987-2009) e da Editora Escuta (1987-2009), autor de Psicopatologia Fundamental (2000) e de Erotomania com German E. Berrios (2009), entre outros livros e numerosos artigos.

Universitário:

Programa de Estudos Pós-Graduados em Psicologia Clínica

Pontifícia Universidade Católica de São Paulo

Rua Ministro Godoy, $939-4^{\circ}$ andar.

05015-000 São Paulo, SP/Br.

Profissional (Professional):

Rua Tupi, $397-10^{\circ}$ andar - sala 103

01233-001 São Paulo, SP

Telefax: 55113825.8573

e-mail: mtberlin@uol.com.br

Rev. Latinoam. Psicopat. Fund., São Paulo, v. 14, n. 3, p. 419-425, setembro 2011 